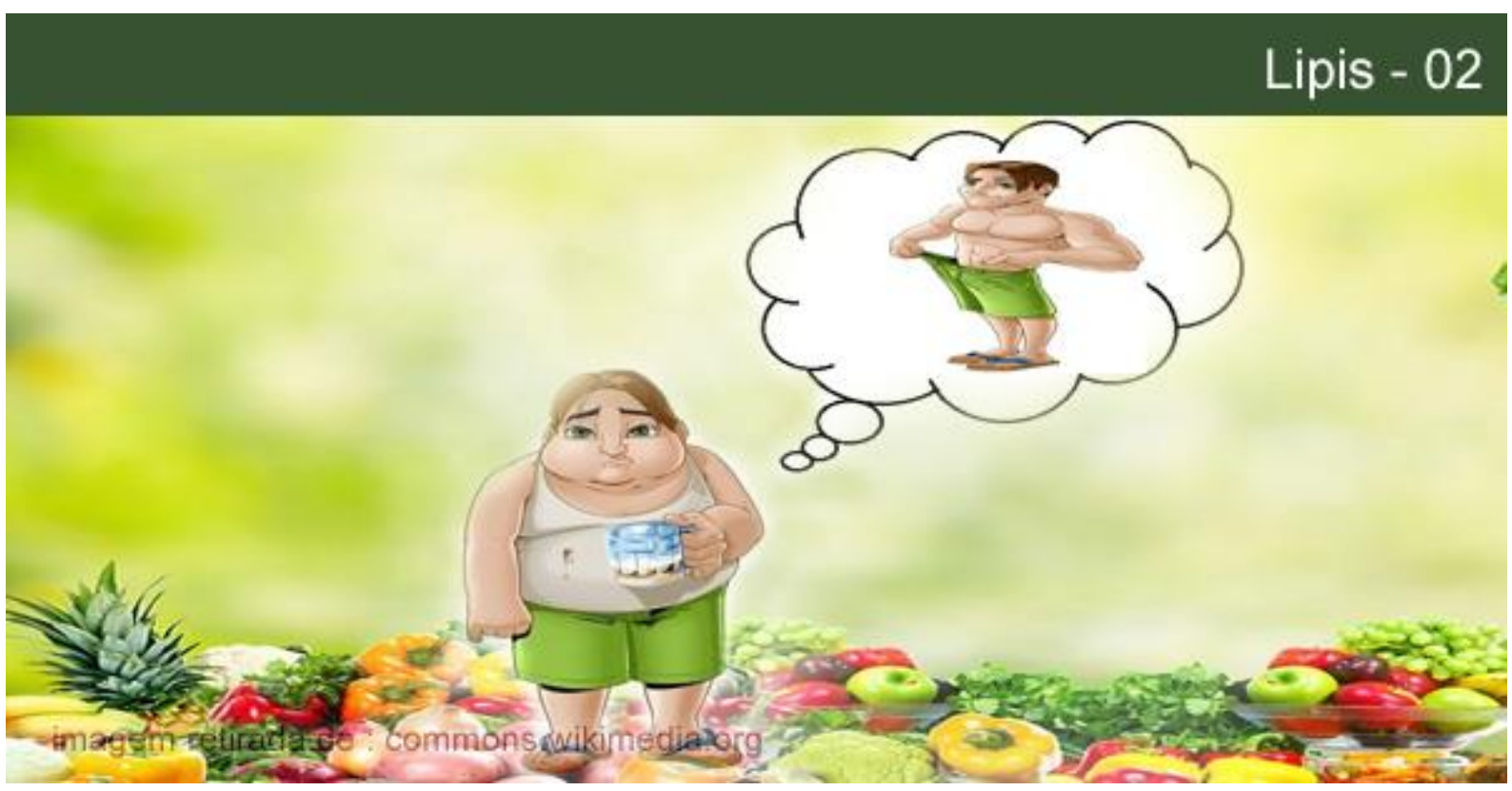

\title{
O PESO QUE NÃO APARECE NA BALANÇA: SOFRIMENTO PSÍQUICO EM UMA SOCIEDADE OBESOGÊNICA E LIPOFÓBICA ${ }^{1}$
}

\author{
Monica Vanderlei Vianna \\ Doutora em Psicologia Clínica pela Pontifícia Universidade Católica do Rio de Janeiro (PUC-RJ). \\ Pesquisadora do Lipis (Laboratório Interdisciplinar de Pesquisa e Intervenção Social) da PUC-Rio. E-mail: \\ viannamonica@hotmail.com.
}

Resumo: O presente artigo propõe uma reflexão sobre o sofrimento psíquico possivelmente instaurado pelo processo de subjetivação e construção da identidade experimentados em um ambiente sociocultural obesogênico e com valores paradoxalmente lipofóbicos. Partindo do preceito que as psicopatologias trazem em si traços do contexto social e histórico no qual estão inseridas, buscou-se através de um referencial teórico psicanalítico, pensar como um ambiente que promove a obesidade e concomitantemente condena os que sucumbem ao excesso de peso contribui para o aumento de manifestações psíquicas relacionadas ao corpo e a alimentação. Para tanto, abordamos questões referentes aos estigmas arreigados à obesidade, à edificação da lipofobia na contemporaneidade, assim como as relações com declínio dos conflitos psíquicos em detrimento dos sintomas corporais na atualidade.

Palavras-chave: Obesidade. Sofrimento Psíquico. Corpo.

\section{THE WEIGHT THAT DOES NOT SHOW UP IN THE SCALE: PSYCHOLOGICALSUFFERING IN A OBESOGENIC AND LIPOPHOBIC SOCIETY}

Abstract: This article proposes a reflection on the psychic suffering possibly established by the process of subjectivation and identity construction experienced in an obesogenic sociocultural environment with paradoxically lipophobic values. Starting from the precept that the psychopathologies bring in themselves traces of the social and historical context in which they are inserted, it was sought through a theoretical reference psychoanalytic, to think like an environment that promotes the obesity and concomitantly condemns those who succumb to the excess weight contributes to the increase of psychic manifestations related to the body and the

${ }^{1} \mathrm{O}$ artigo faz parte da pesquisa de doutorado orientada pela prof ${ }^{a}$. Dra. Junia de Vilhena, com o título: Compulsão Alimentar e Cirurgia Bariátrica: a fome que o bisturi não alcança. Realizada na Pontifícia Universidade Católica do Rio de Janeiro - PUC-Rio, com financiamento CAPES.

\section{POLÊM!CA $\mid$ LABORE (E)}

Polêmica - Revista Eletrônica da Uerj - Rua São Francisco Xavier, 524, $1^{\circ}$ andar

bloco D, sl.1001 • Tels.: +55 21 2334-4088/4087 • http://www.e-publicacoes.uerj.br/index.php/polemica/index http://www.labore.uerj.br • laboreuerj@yahoo.com.br 
feeding. In order to do so, we address issues related to the stigmas attached to obesity, the construction of lipophobia in contemporary times, as well as the relationship with the decline of psychic conflicts to the detriment of current bodily symptoms.

Keywords: Obesity. Psychological Suffering. Body.

\section{Introdução}

O crescimento da obesidade no mundo vem sendo noticiado, quantificado e comentado em profusão e com alarde tanto pela mídia quanto pelas ciências sociais e médicas. Retratada como uma pandemia moderna ou como o maior problema de saúde pública da atualidade, a obesidade é condenada de forma implacável pela sociedade contemporânea e representada, muitas vezes, como um problema moral, uma falha de conduta ou como sinal de desorganização da vida pessoal e emocional.

Dessa forma, testemunhamos o surgimento de uma sociedade lipofóbica, que estabelece valores associados ao culto do corpo, fortemente realçados pela mídia, marcando socialmente os indivíduos obesos como portadores de um estigma. A condição social do obeso está atrelada às discriminações de diversas matizes, nas quais se associa uma gama de conceitos e valores negativos, criando uma depreciação que abarca todos os segmentos da vida cotidiana.

O termo "lipofobia" foi criado na década de 60 pelo norte-americano Claude Fischler (2001) para designar o rechaço à gordura de origem animal e apontar concomitantemente a silhueta magra como modelo de beleza e saúde. Esse padrão cultural, estético e higienista foi legitimado pelo discurso biomédico que, ao representar o corpo, enfatiza as questões quantitativas e os parâmetros biológicos, desprezando as questões subjetivas e as referências socioculturais, o que torna o modelo um tanto reducionista.

Fugindo de uma abordagem simplista, o presente artigo pretende refletir sobre as possíveis repercussões psíquicas nos sujeitos contemporâneos, decorrentes de um ambiente sociocultural paradoxalmente obesogênico e lipofóbico.

As implicações psíquicas de uma subjetivação permeada por essa incongruência social específica remonta aos aspectos históricos que edificaram a lipofobia e seus desdobramentos na atualidade, assim como os fatores sociais que contribuíram para a escalada da obesidade, um fenômeno contemporâneo, que se converteu em uma das doenças que mais cresce no mundo (segundo os dados do maior estudo global já feito sobre Índice de Massa Corporal -

\section{POLÊM!CA $\mid$ LABORE}


IMC, a população obesa mundial passou de 105 milhões em 1975 para 641 milhões em 2014 (OMS, 2014).

A partir da análise das informações colhidas em pesquisa acadêmica de doutorado em Psicologia Clínica, sobre obesidade, cirurgia bariátrica e transtornos alimentares, realizada na PUC-Rio, propomos uma reflexão sobre elementos que ajudem a pensar o aumento da incidência de temas relativos à obesidade na clínica psicanalítica contemporânea, seja na forma de sofrimento psíquico e/ou sintomas corporais.

\section{Sociedade obesogênica}

A palavra obesidade deriva do latim obesîtas, composta a partir da junção do prefixo $o b$, que significa "em", "por" ou "sobre", com o verbo edere, comer ou devorar. Em latim, obesus significa completamente nutrido ou nutrido em excesso (CUNHA, 2007).

Ao afirmar que a sociedade contemporânea é obesogênica, estamos nos referindo ao aumento considerável nos níveis de obesidade na população mundial resultante da conjugação de diversos fatores. Tal fenômeno ficou conhecido como transição nutricional, no qual houve uma diminuição significativa nas taxas de desnutrição infantil e um acelerado aumento da prevalência de sobrepeso e obesidade na população (BATISTA FILHO; RISSIN, 2003). Essa transição surge como consequência de alterações no modo de vida da população em geral, principalmente como resultado da industrialização, urbanização, sedentarismo e saída da mulher para o mercado de trabalho.

As mudanças no estilo tradicional de vida das populações decorrentes de processos como a urbanização, industrialização e o avanço da tecnologia impactaram diretamente nas formas de trabalho, nos hábitos alimentares e no acesso aos serviços de saúde básicos. A população do campo diminuiu, enquanto a da cidade aumentou consideravelmente, da mesma forma, a taxa de natalidade diminuiu e a expectativa de vida aumentou. Todos esses fatores são influenciados e influenciam as mudanças no padrão energético da dieta e na diminuição da atividade física, ou seja, contribuíram para o quadro mundial de obesidade na atualidade.

O impacto dessas mudanças no peso da população mundial é evidenciado em números; de acordo com o levantamento realizado em 2014 pela Organização Mundial de Saúde (OMS), a obesidade atinge cerca de 600 milhões de pessoas no mundo. No Brasil, os

\section{POLÊM!CA $\mid$ LABORE}


dados divulgados pelo Ministério da Saúde em 15 de abril de $2015^{2}$ revelam que 17,9\% da população apresenta obesidade e o número sobe para 52,5\% da população se incluirmos as pessoas com sobrepeso.

Apesar das estatísticas relacionadas ao crescimento da obesidade no mundo, não seria correto empregar a expressão "epidemia da obesidade" (frequentemente utilizada pela mídia e pesquisas de uma forma geral). Isso porque epidemia significa o rápido alastramento de doenças infectocontagiosas, o que não se aplica para obesidade, já que não é causada por vírus, nem é contagiosa. A obesidade é conceituada como uma doença crônica de etiologia multifatorial (fatores genéticos, econômicos, culturais, sociais, ambientais e políticos) caracterizada pelo excesso de gordura no corpo, sendo que os determinantes básicos para as doenças crônicas são reflexos das mudanças sociais, econômicas e culturais.

Obesidade não é um transtorno alimentar, logo não é uma doença psiquiátrica. Não existe um perfil psicológico ou uma estrutura psíquica única para todos os sujeitos obesos, sendo temerária a generalização dos problemas psicológicos para todos os casos de obesidade. A obesidade é, segundo a OMS (2014), uma doença endócrina, nutricional e metabólica, não podendo ser confundida com distúrbios mentais ou comportamentais (VIANNA, 2016).

As necessidades nutricionais da nossa espécie não se enquadram em uma dieta única e ideal, pois a sobrevivência humana e sua singularidade estão diretamente ligadas à extraordinária variedade da nossa alimentação. Comer sempre esteve culturalmente ligado a festividades, celebrações e aos rituais de cada povo, assim como às mais diversas religiões e crenças. Alimentar-se é um ato ao mesmo tempo fisiológico, emocional, psíquico, social e cultural.

Não existe uma dieta alimentar que seja ideal para todas as pessoas, muito menos a constante dicotomia que vemos na classificação dos alimentos, rotulados como bons ou ruins, permitidos ou proibidos, puros ou tóxicos. A historiadora inglesa Foxcroft (2013), em seu livro "A tirania das dietas", afirma que nossa cultura vive em busca da dieta perfeita, e isso gera sentimentos profundos de infelicidade e insegurança. Para a autora, seria preciso repensar nossa relação com a comida e retomar uma abordagem simples para obtermos uma dieta fisiológica e psicologicamente saudável.

\footnotetext{
${ }^{2}$ Os números são da pesquisa Vigitel 2014 (Vigilância de Fatores de Risco e Proteção para Doenças Crônicas por Inquérito Telefônico), que coletou informações nas 26 capitais brasileiras e no Distrito Federal. Foram realizadas 41 mil entrevistas para o levantamento.
}

\section{POLÊM!CA $\mid$ LABORÉ}


A lipofobia, de mãos dadas com as dietas da moda, impregna a alimentação de culpa, vergonha e medo, como tão bem ilustra Costa nessa passagem do livro "O vestígio e a aura":

\begin{abstract}
Qualquer comentário sobre hábitos alimentares, por exemplo, desencadeia, em geral, uma tagarela, bizarra e infantilizada competição sobre quem faz mais exercícios, quem come menos gordura; quem é capaz de perder mais quilos em menos tempo; quem deixou de fumar há mais tempo; quem ingere mais vegetais, alimentos e fármacos naturais etc. Em paralelo a isto, todo consumo de comidas com alto teor calórico é precedida de verdadeiros atos de constrição e rituais preventivos de expiação da falta a ser cometida. Os que não aceitam jogar o jogo são vistos como problemáticos do ponto de vista emocional, já que se entregam, sem escrúpulos, à autodestruição física e moral. Afinal, pensamos, sem a boa forma, não teremos oportunidade alguma de ser vencedores. O mal do século é o mal do corpo (COSTA, 2004, p. 199).
\end{abstract}

\title{
Cultura lipofóbica
}

Sant'anna (2005) estudou a história do corpo e da obesidade e nos mostra que, apesar da evidente complexidade subjacente à história da aparência física e de seu percurso intrincado, não podemos negar que a aversão aos gordos vem de longa data.

Segundo Sant'anna (2005), o termo obesidade foi usado pela primeira vez no século XVII por Tobias Venner, já neste primeiro momento era apontado como uma enfermidade. Todavia, a magreza costumava ser mais preocupante do que o excesso de peso. Numa época na qual a magreza estava relacionada a padrões de doença, fome e privação, a obesidade ainda podia ser considerada uma condição favorável. Quando a fartura era privilégio dos ricos, a gordura era de certa forma, sinônimo de saúde e prosperidade, enquanto a esbeltez sugeria miséria, doença e dificuldade.

Fischler (2001), em suas investigações sobre as diversas representações da obesidade ao longo dos tempos, lembra que o excesso de peso sempre esteve relacionado com a capacidade de obter alimento, fosse essa capacidade decorrente da maior força física ou mesmo fruto de violação das regras de divisão dos mantimentos. Das duas formas recai sobre o gordo uma aura negativa, que passeia entre a violência e a deslealdade.

Ao longo do século XX, concomitante às mudanças nos padrões de alimentação da população e ao advento da supervalorização do corpo, o fenômeno da lipofobia se instalou com força e definitivamente (GRACIA-ARNAIZ, 2010).

O corpo é atravessado pelo simbólico e pelas construções sociais, assumindo uma especificidade em cada cultura e sofrendo variações de acordo com o tempo histórico ou a geografia na qual está inserido. É consenso entre psicanalistas, sociólogos, filósofos e

\section{POLÊM!CA $\mid$ LABORE}


antropólogos que a preocupação com o corpo vem assumindo centralidade cada vez maior na vida social contemporânea e tornou-se elemento primordial no projeto de construção da identidade (GIDDENS, 1997).

O sociólogo francês Le Breton (2003, p. 97) afirma que o "corpo é a interface entre o social e o individual, a natureza e a cultura, o psicológico e o simbólico". O autor introduz a ideia de corporeidade como uma realidade construída do corpo, com múltiplas significações culturalmente operantes. O fenômeno da corporeidade é complexo, pois aborda um objeto incerto e ambíguo. Para evitar modelos reducionistas de interpretação, faz-se necessário um pensamento que convoque a interdisciplinaridade entre as Ciências Sociais e Humanas (Etnologia, Psicologia, Sociologia, Psicanálise) e as Ciências Biomédicas.

Ainda segundo Le Breton (2003), a existência do indivíduo é indissociável das suas formas corporais. A condição humana é a condição corporal, por isso o sujeito se constrói e busca possuir um corpo aprovado pelos referenciais da sociedade à qual pertence. Quando seu corpo não é aprovado socialmente ou encontra-se em desacordo com os parâmetros culturais, a frustração pode levar a uma desorganização e perseguição egóica transfiguradas em autoestigmatização.

Bourdieu (1988) demonstra que a linguagem corporal é marcada pela distinção social, e através dela, percebemos códigos de identidade e de alteridade que indicam a presença de universos simbólicos e nos ajudam a entender o mundo que os envolve. Segundo o autor, a comunicação corporal é extremamente reveladora, sendo o consumo alimentar, cultural e a forma de apresentação (incluindo o consumo de vestuário, artigos de beleza, higiene e de cuidados e manipulação do corpo em geral) as três mais importantes maneiras de distinguir-se socialmente.

O corpo é a mais irrecusável objetivação do gosto de classe que se manifesta de diversas maneiras. Em primeiro lugar, no que tem de mais natural em aparência, isto é, nas dimensões (volume, estatura, peso) e nas formas (redondas ou quadradas, rígidas e flexíveis, retas ou curvas, etc.) de sua conformação visível, mas que expressa de mil maneiras toda uma relação com o corpo, isto é, toda uma maneira de tratar o corpo, de cuidá-lo, de nutri-lo, de mantê-lo, que é reveladora das disposições mais profundas do habitus (BOURDIEU, 1988 p. 188).

A preocupação com a apresentação do corpo transformou certos rituais de cuidado em necessidade básica da vida cotidiana. Para tanto, as dietas da moda, procedimentos estéticos e atividades físicas regulares são os principais recursos adotados pelos indivíduos para tornarem

\section{POLÊM!CA $\mid$ LABORE}

Polêmica - Revista Eletrônica da Uerj - Rua São Francisco Xavier, 524, $1^{\circ}$ andar

bloco D, sl.1001 • Tels.: +55 21 2334-4088/4087 • http://www.e-publicacoes.uerj.br/index.php/polemica/index

http://www.labore.uerj.br • laboreuerj@yahoo.com.br 
ou manterem seus corpos adequados. Os espaços de culto ao corpo se tornam uma das principais maneiras de se estabelecer formas de sociabilidade, construir marcas identitárias e de distinção social (CASTRO, 2003). Neste contexto, o corpo configura-se, cada vez mais, como território de construção de identidade.

Segundo Barthes (1982, p. 645), a imagem corporal é o resultante da influência que o ambiente exerce sobre o sujeito. O autor afirma que: "meu corpo é para mim mesmo a imagem que eu creio que o outro tem deste corpo". Neste início do século XXI, vivemos a hegemonia da tríade "beleza, juventude e saúde" representando de forma precisa o culto social ao corpo perfeito. Esse movimento é estruturalmente sustentado pelo meio científico e pela mídia, que validam e difundem a ideia de que os indivíduos são responsáveis pelo desenvolvimento dos valores fundamentais desta tríade, e por isso são culpados pela sociedade caso não consigam alcançá-los (NOVAES, 2011). O corpo enquanto instrumento da construção da identidade, diante da feroz influência das imposições sociais, se torna alvo das mais diversas formas de controle para atingir o modelo que representa a confluência entre saúde e beleza.

Ao reforçar no imaginário social que o corpo magro é uma condição prioritária para saúde física e uma vida social plena, estabelecemos um ambiente opressor para os corpulentos. Através da supervalorização da magreza enquanto ideal de beleza, felicidade e sucesso, cria-se uma pressão cultural para perder e controlar constantemente o peso, reforçada pela associação da gordura como um símbolo de falência moral que justifica o estigma sobre a obesidade.

De acordo com Goffman (1988), o conceito de estigma refere-se a qualquer atributo pessoal que é "altamente desacreditador" para quem o possui, e esses atributos incluem a “estigmatização grupal”, "aversão do corpo" e "falhas no carácter individual”, estando todas as três dimensões associadas à condição de pessoa obesa.

Ainda segundo Goffman (1988), a construção de estigmas é uma característica das sociedades. Ao definirmos categorias mais ou menos rígidas sobre atributos e/ou características que consideramos normais ou comuns do ser humano em determinado momento cultural e histórico, criamos uma identidade social.

Aqueles sujeitos com características que não se encaixam nas categorias de ser humano normal passam a ser considerados portadores de um estigma. A identidade social dos

\section{POLÊM!CA $\mid$ LABORE}


sujeitos estigmatizados retrata a frustração na tentativa de corresponder às expectativas de normalidade determinadas pela sociedade em questão. Podemos dizer que o estigma, então, funciona como uma forma de classificação social, que passa pelo corpo e pelas relações sociais dos sujeitos.

Dessa forma, os cuidados com o corpo se apresentam como uma solução obrigatória para enfrentar os julgamentos e expectativas sociais. Os investimentos estéticos estão diretamente relacionados à visibilidade social e à exposição ao olhar do outro. Segundo Novaes (2011), a indústria da beleza e a mídia investem em um jogo de espelhos produzido entre o corpo e o olhar do outro, no qual são construídas e ao mesmo tempo inibidas a autoestima e a autoimagem.

Ao imputar aos obesos a incapacidade de controlar sua vontade em relação à comida, aproximamos ainda mais a obesidade da fraqueza e pouca tenacidade moral. Ela chega a ser comparada com as dependências químicas, e mais uma vez são reforçados os estigmas e a culpa do sujeito por sua aparência. Esses estigmas, que associam a causa do problema com o comportamento do indivíduo (como a AIDS e a obesidade), provocam menos sentimentos de simpatia do que os estigmas que não associam a causa do problema com o comportamento do indivíduo (como cegueira, anorexia, câncer e paraplegia). "Nada é mais punitivo do que atribuir um significado a uma doença quando esse significado é... moralista" (SONTAG, 1984).

Colocar a questão da obesidade sob a estrita responsabilidade do indivíduo obeso, centralizando o problema no controle do seu corpo e da sua vontade, vem se mostrando uma ótima estratégia de marketing para inúmeros produtos disponíveis em profusão no mercado de consumo. A obesidade foi declarada uma pandemia pela OMS em 2005, e evidentemente, as indústrias farmacêutica, cosmética e alimentícia tiveram um enorme interesse nessa declaração. Se há uma pandemia da obesidade divulgada de modo espetacular pelos meios de comunicação de massa, é quase inevitável que esta provoque uma pandemia de dietas, remédios para emagrecer e tratamentos estéticos.

Existe uma carga ideológica por trás da imposição da magreza e da modelagem dos corpos: todos os investimentos nos cuidados com a aparência são permeados pela lógica do consumo. Quanto mais atormentados estivermos pelo olhar do outro, maior será o nosso esforço e investimento para se desvencilhar dessa angústia. A lógica capitalista prega que o

\section{POLÊM!CA $\mid$ LABORË}


prazer e o sucesso só serão possíveis se forem precedidos de esforço, empenho, determinação e investimento: "No pain, no gain".

Ao refletir sobre a lógica capitalista, difundida pela cultura de massa e a globalização, na qual o valor pessoal é vinculado ao autocontrole e poder de consumo, fica um pouco mais fácil compreender a difusão da lipofobia na sociedade contemporânea. Essa lógica se empenha em colocar a obesidade como uma condição de preguiça e pouca força de vontade no imaginário popular. Como afirmou Guy Debord (1997), em sua importante obra "A sociedade do espetáculo", a evolução da sociedade capitalista burguesa é um caminho inexorável que percorreu o SER > TER > PARECER. Numa cultura lipofóbica, o primeiro mandamento é parecer magro, consequentemente o pavor ou medo mórbido de engordar deixa de ser uma distorção que caracteriza apenas daqueles que padecem com os transtornos alimentares.

\section{Sofrimento psíquico}

O impacto da cultura sobre a organização psíquica dos indivíduos e consequentemente sobre a constituição de uma psicopatologia peculiar aos diferentes tempos não é uma novidade para a psicanálise. A partir da premissa que as psicopatologias trazem em si um traço de sua época, torna-se fundamental analisar a maneira como o sofrimento do indivíduo aparece em determinado contexto histórico.

Um ambiente que estimula, promove a obesidade e concomitantemente condena, exclui e pune os que sucumbem ao excesso de peso, contribui para o aumento de manifestações psíquicas relacionadas ao corpo e à alimentação.

$\mathrm{Na}$ atualidade, observa-se uma mudança no modo de subjetivação a partir de uma maior pregnância da produção sintomática na dimensão do corpo do que na esfera do conflito psíquico. Isso pode ser verificado na grande demanda clínica de casos onde os sintomas e sofrimentos se relacionam com a concretude do corpo e da alimentação, assim como nos diversos estudos que corroboram a magnitude e impacto da lipofobia social no psiquismo do sujeito contemporâneo:

Um estudo recente concluiu que $11 \%$ dos americanos abortariam um feto se lhes dissessem que o bebê teria tendência à obesidade... Em outra pesquisa, crianças com cerca de cinco anos de idade, quando solicitadas a identificar pessoas de boa aparência, escolhem fotos de pessoas magras. Crianças da escola primária apresentam atitudes mais negativas em relação aos obesos do que aos brigões,

\section{POLÊM!CA $\mid$ LABORE}


deficientes ou crianças de raças diferentes. Os professores subestimam a inteligência dos obesos e superestimam a inteligência dos esbeltos. Os universitários obesos têm menos probabilidade de receber bolsas de estudo (PIPHER, 1998 p. 268).

Vários estudos demonstraram que crianças de 6 a 10 anos de idade tinham tendência para atribuir mais características negativas não relacionadas com o peso às crianças obesas do que às que possuíam peso normal, nomeadamente "preguiçosas", "sujas", "estúpidas" e "feias" (HAINES; NEUMARK-SZTAINER, 2004). O mesmo é verificado no caso de avaliações de pessoas adultas (OGDEN, 2000).

Numa pesquisa realizada por Rand e Macgregor (1991), foram entrevistados pacientes que fizeram cirurgia bariátrica e que perderam pelo menos $45 \mathrm{~kg}$ em um período de três anos. Estes foram questionados sobre quais doenças ou deficiências preferiam ter em vez de voltarem a ser obesos: todos responderam que preferiam ser surdos, disléxicos, diabéticos ou terem doenças cardiovasculares a voltarem a ser obesos; 9 em cada 10 pacientes responderam que preferiam amputar uma perna e 8 em cada 10 preferiam ser totalmente cegos a serem obesos.

Estas pesquisas demonstram claramente que a lipofobia classifica a obesidade acima de tudo como um problema moral, além de evidenciar o sofrimento emocional gerado pela corpulência. A tentativa da mídia e da indústria de vincular o corpo magro às ideias de saúde e qualidade de vida perde sua sustentação e encaramos a dura realidade por trás da idealização da magreza. Maroun e Vieira alcançam o cerne da questão quando afirmam que:

Não se trata mais de aceitar o corpo como ele é, mas sim de corrigi-lo, transformá-lo e reconstruí-lo. O imaginário contemporâneo de muitos, busca nos corpos, assim como em outros objetos, uma possível verdade sobre si a mesma que a sociedade parece não conseguir mais lhes proporcionar. Assim, na falta de realizar-se em sua própria existência, procuram realizar-se por meio de seus corpos (MAROUN; VIEIRA, 2008, p. 173).

As novas configurações subjetivas utilizam cada vez mais o corpo como via privilegiada para a expressão da subjetividade. Enquanto o mal-estar freudiano era marcado por um conflito psíquico, o sofrimento atual se faz cada vez mais presente nos registros do corpo e da ação (FORTES, 2010). Refletir sobre o aumento da incidência de sintomas relacionados ao corpo, à alimentação e às compulsões na atualidade nos obriga a pensar na supervalorização do corpo na sociedade contemporânea, nos paradoxos da cultura alimentar e na construção do olhar pejorativo e degradante que marca a obesidade nos dias de hoje.

\section{POLÊM!CA $\mid$ LABORE}


Byung-ChulHan (2016) em seu livro "A sociedade do cansaço", aponta para uma mudança paradigmática advinda da transição da sociedade disciplinar, cunhada por Foucault, para sociedade do desempenho vivida no século XXI. Nessa transição o inconsciente social transfigura-se do registro do dever para o registro do poder, contudo, o autor sublinha que o poder não cancela o dever, ou seja, o sujeito do desempenho permanece disciplinado.

Segundo o autor, a queda da instância disciplinar, dominadora, não leva a liberdade do sujeito, pelo contrário, o sujeito do desempenho passa a ser submisso a si mesmo. Desta forma, se entrega ao que ele chama de liberdade coercitiva ou livre coerção. Uma liberdade paradoxal na qual explorador e explorado, agressor e vítima coabitam a mesma morada, gerando uma auto-exploração que caminha de mãos dadas com um falso sentimento de liberdade. Ainda segundo Byung-ChulHan (2016, p. 30), “Os adoecimentos psíquicos da sociedade de desempenho são precisamente as manifestações patológicas dessa liberdade paradoxal".

Ehrenberg (1998) apontava para a transição do contexto da norma disciplinar para um mundo onde cada um é incitado à iniciativa individual a partir de uma exigência de tornar-se si mesmo. Esse movimento traz como consequência a mudança da responsabilidade por nossas vidas, que antes se alocava no mundo coletivo e agora recai sobre nós mesmos.

Fortes (2008) reforça a compreensão de que a liberação em relação às exigências sociais não significa o fim das pressões sociais, pelo contrário, se antes havia a repressão proveniente dos interditos, agora existe a imposição da performance. A psicanalista aponta que nas psicopatologias contemporâneas o sujeito sente-se impossibilitado de responder às demandas suscitadas, paradoxalmente, por consequência da suposta liberdade de escolha, e completa:

Em vez de nos culparmos pelo nosso desejo, atormentamo-nos por não conseguir alcançar o nosso ideal de ser. Há um permanente sentimento de vazio que se configura entre o que somos e o que almejamos ser. Se por um lado, a atualidade não tem a culpa como motor da produção de subjetividade, o vazio subjetivo se delineia hoje como um dos efeitos do próprio excesso. Num mundo sem mediação, fica-se à mercê da lógica do ou tudo ou nada (FORTES, 2008, p. 64).

Segundo Costa (2004), as patologias contemporâneas revelariam, por um lado, os fracassos diante dos imperativos da exaltação do Eu, como na depressão e na síndrome do pânico e, por outro lado, uma tentativa de adesão a eles por meio de um excessivo apego ao corpo na exteriorização do sofrimento, como nos sintomas somáticos e nas adições em geral.

\section{POLÊM!CA $\mid$ LABORE}

Polêmica - Revista Eletrônica da Uerj - Rua São Francisco Xavier, 524, $1^{\circ}$ andar

bloco D, sl.1001 • Tels.: +55 21 2334-4088/4087 • http://www.e-publicacoes.uerj.br/index.php/polemica/index

http://www.labore.uerj.br • laboreuerj@yahoo.com.br 
Tanto a depressão quanto a adição seriam efeitos do desinvestimento do espaço psíquico do conflito em detrimento da obrigação de agir e de tornar-se si mesmo.

Nas palavras de Baudrillard (1995, p. 151), juntamente com a libertação física, libertase a pulsão agressiva, "é esta pulsão que alimenta o irreprimível encarniçamento autodestrutivo, irracional, em que a beleza e a elegância, visadas na origem se reduziram a simples álibi para o exercício disciplinar, quotidiano, obsessivo". O corpo se torna um objeto ameaçador, sendo preciso vigiá-lo, reduzi-lo e domá-lo para fins estéticos.

Sabemos que a aversão aos gordos não teve início na época contemporânea, mas foi nesse período que se intensificou e acentuou sua conotação de desvio de caráter, moral e emocional. A lipofobia tornou-se um imperativo e o sujeito obeso ficou enclausurado em sua aparência, sem espaço para ser, mostrar ou construir nada que não remeta a seu excesso adiposo. O corpo chega antes do sujeito e o impede de viver sua singularidade.

Frequentemente escutamos nos relatos clínicos que o sujeito gordo recebe ofensas e injúrias abertamente no ambiente familiar, profissional e até mesmo de profissionais de saúde. Eles nos contam que por serem gordos não podem comer em público, ficar doentes, se locomover em ônibus/avião ou comprar vestimentas sem que isso atraia olhares de reprimenda e desgosto. Tudo remete ao peso e a solução de todos os problemas é emagrecer. Para tentar controlar a aparência física, recorre-se à medicalização crescente do corpo e da alimentação: são oferecidas com total naturalidade dietas excessivamente restritivas, produtos de origem duvidosa, cirurgias invasivas e procedimentos estéticos dolorosos. Mesmo diante de tamanha pressão e do ataque constante, os números da obesidade continuam crescendo e se agravando em todo mundo.

Olhar para subjetividade das pessoas, para além da obesidade, nos obriga a levar em conta as vivências sociais e seu impacto na constituição do sujeito. A corpulência vem impondo um sofrimento emocional ao sujeito, uma vez que vai contra imperativos fortemente arraigados na nossa cultura.

Para a Psicanálise, o corpo pertence à ordem do simbólico e se apresenta nas dimensões do discurso, desejo e representação. Ele é revestido de significados construídos através da cultura e do próprio sujeito. A maneira como os imperativos da cultura e da sociedade são assimilados evidencia seu mal-estar, ou seja, o que escapa à sua capacidade de elaboração psíquica desencadeia sintomas e sofrimento.

\section{POLÊM!CA $\mid$ LABORE}


A condição obesa pode produzir impacto na subjetividade e constituição psíquica, acompanhado de importantes limitações sociais. O reflexo de uma sociedade lipofóbica, que transforma um pensamento médico que liga obesidade à falta de saúde e morte em algo absoluto e irrestrito, atua como uma resposta única para um problema complexo e multifacetado. Esse engessamento produz sofrimento psíquico com capacidade de adicionar psicopatologias ao já extenso hall de comorbidades ligadas ao excesso de peso.

Não se trata de uma escolha entre lipofobia e apologia à obesidade. Não se nega o caráter deletério do excesso de peso ao organismo, pois sua associação com diversas comorbidades como doenças cardiovasculares, endócrinas, infertilidade, doenças gastrointestinais, ortopédicas e infecções é uma realidade estudada e comprovada (COUTINHO, 1998; HALPERN, 1998; HALPERN; MANCINI, 2002). As chamadas “doenças do peso" causam inúmeros prejuízos à saúde e são responsáveis pela diminuição da expectativa de vida. Ocorre que as complicações físicas coexistem, sem suplantar ou minimizar os severos prejuízos sociais, emocionais e psíquicos impostos pela lipofobia.

Viver em uma sociedade lipofóbica, numa cultura que reforça constantemente a insatisfação com o corpo, só dificulta as tentativas de resolver os aspectos obesogênicos desta mesma sociedade. A depreciação moral e exclusão social afetam negativamente o tratamento da obesidade, gerando desmotivação, fracassos sucessivos e grande frustração. Dessa forma, as atuais práticas clínicas e os diferentes tipos de procedimentos para controle do peso acabam gerando ainda mais sofrimento (RIBEIRO; ZORZETTO, 2004):

\footnotetext{
O que caracteriza os sujeitos contemporâneos é o desejo do corpo absolutamente livre de todo traço de adiposidade, seja a que compõe os tecidos, seja a que circula como colesterol. Só o músculo é nobre. A gordura não aparece mais como uma reserva de segurança, signo de uma gestão econômica e racionalizada, e sim uma invasão parasitária, uma acumulação anormal e aproveitadora, uma retenção nefasta (FISCHLER, 2001, p. 317).
}

Com o reforço constante dos valores lipofóbicos, a insatisfação com o corpo se tornou uma regra e os transtornos alimentares são cada vez mais frequentes entre homens e mulheres, principalmente na adolescência. Esse respaldo social também contribuiu para associação da obesidade com outros transtornos mentais, como depressão e ansiedade. Nestes casos, constata-se uma via de mão dupla associativa. Ou seja, os transtornos mentais favorecem o

\section{POLÊM!CA $\mid$ LABORE}


desenvolvimento da obesidade, assim como a obesidade aumenta a incidência dos transtornos mentais ${ }^{3}$.

Fandiño et al. (2004), relataram que existe um aumento da psicopatologia em pacientes gravemente obesos que procuram tratamento para emagrecer. Sendo que os sintomas depressivos, de ansiedade e do comportamento alimentar estão diretamente relacionados com o julgamento social e moral, preconceitos, estigmas e discriminações enfrentados pelos obesos. Outras pesquisas também corroboram que grande parte das doenças psiquiátricas vinculadas à obesidade são fruto dessa impossibilidade de adequação e aceitação imposta pelo social (SEGAL; FANDIÑO, 2002; FELIPPE et al., 2004).

\section{Conclusão}

A experiência corporal sempre foi modificada e perpassada pela cultura. $\mathrm{Na}$ atualidade, o sofrimento psíquico se dirige ao corpo como objeto privilegiado, manifestandose através da compulsão, dos transtornos alimentares e da obesidade. $\mathrm{O}$ corpo fala enquanto o sujeito se cala. Na concretude da expressão corporal, a elaboração da dor psíquica se inviabiliza, fazendo acreditar que a saída para o mal-estar emocional se encontra nas dietas da moda e nos procedimentos estéticos.

Em um contexto cultural no qual a aparência dita regras e legitima o sujeito socialmente, o excesso de gordura corporal é visto e vivido como uma dupla barreira, entre o sujeito e sua identidade, mas também entre o sujeito e os seus pares. O estigma perpetua preconceitos, transformando uma característica física em um desfio moral que paralisa e adoece.

Os paradoxos de uma sociedade obesogênica e lipofóbica apontam para uma realidade onde o corpo deixou de representar uma identidade social ou expressão de um estilo de vida e passou a ocupar o papel da própria pessoa, ou seja, responde como a expressão psíquica do sujeito. Dessa forma, observamos a ascensão corporal em sua intensidade e importância, mas ao mesmo tempo em sua vulnerabilidade e perigo. Afinal, não é permitida nenhuma inadequação ao padrão vigente, e quem fugir das normas de peso e formato corporal será sumariamente condenado à pena de discriminação social, ao julgamento moral e condenado ao sofrimento e exclusão.

\footnotetext{
${ }^{3}$ Também existem algumas medicações psiquiátricas que podem provocar ganho ponderal e alterações lipídicas e metabólicas. Entre elas os antipsicóticos atípicos, estabilizadores de humor e alguns antidepressivos.
}

\section{POLÊM!CA $\mid$ LABORE}




\section{Referências}

AMANTINO, M. (org.). História do corpo no Brasil. São Paulo: Unesp, 2011. p. 477-506.

BARTHES, R. Encore lecorps. Paris: Critique,198. n. 423-424, p. 645-654.

BATISTA-FILHO M., RISSIN A. A transição nutricional no Brasil: tendências regionais e temporais. Cad. Saúde Pública, 2003, 19(supl. 1), S181-S191.

BAUDRILLARD, J. A sociedade de consumo. Lisboa: Edições 70, 1995.

BOURDIEU, P. Questions de sociologie. Paris: Leséditions de minuit, 1988.

CASTRO, A. L. de. Culto ao corpo e sociedade: mídia, estilos de vida e cultura de consumo. São Paulo: Annablume, 2003.

COSTA, J. F. O vestígio e a aura: corpo e consumismo na moral do espetáculo. Rio de Janeiro: Garamond, 2004.

COUTINHO, W. Obesidade: conceitos e classificação. In: NUNES, M. A. et al. Transtornos alimentares e obesidade. Porto alegre: Artmed, 1998. p. 197- 202.

CUNHA, A. G. Dicionário etimológico da língua portuguesa. 3.ed. Rio de Janeiro: Lexikon, 2007.

DEBORD, G. A Sociedade do Espetáculo. Tradução: Estela dos Santos Abreu. Rio de Janeiro: Contraponto, 1997.

EHRENBERG, A. La fatigue d'êtresoi. Paris: Odile Jacob, 1998.

FANDIÑO, J. et al. Bariatricsurgery: clinical, surgicalandpsychiatricaspects. Revista de Psiquiatria do Rio Grande do Sul, v. 26, n. 1, p. 47-51, 2004.

FELIPPE, F. M. L. et al. O peso social da obesidade. Comunicação e Saúde: Revista Digital, v. 1, n. 1, 2004.

FELIPPE, F. M. L. et al. Obesidade e mídia: o lado sutil da informação. Revista acadêmica do grupo comunicacional de São Bernardo: publicação digital, v. 1, n. 2, 2004.

FISCHLER, C. Les alimentations particulières. Paris: Odile Jacob, 2013.

L'homnivore. Paris: Odile Jacob, 2001.

FORTES, I. A dimensão do excesso: Bataille e Freud. Ágora (PPGTP/UFRJ). v. XIII. p. 9-22, 2010. 2009. A psicanálise face ao hedonismo contemporâneo. Revista Mal-Estar e Subjetividade, v. 9, p. 29-40,

Masoquismo e desamparo no sofrimento contemporâneo. Pulsional Revista de Psicanálise, ano 21, $\mathrm{n}^{\circ}$ 4, p. 27-38, 2008.

FOXCROFT, Louise. A Tirania das dietas. São Paulo: Editora Três Estrelas, 2013.

GRACIA ARNAIZ M. Fat bodies and thin bodies: Cultural, biomedical and Market discourses on obesity. Appetite, 55, 219-225, 2010.

GIDDENS, A. Modernidade e Identidade Pessoal. Oeiras: Celta, 1997.

\section{POLÊM!CA $\mid$ LABORE}


GILMAN, S. L. Fat: a cultural history of obesity. Cambridge: UK Malden, MA, USA, 2010.

GOFFMAN E. Estigma: Notas sobre a manipulação da identidade deteriorada. 4. ed. Rio de Janeiro: Ltc; 1988.

HAINES, J.\& NEUMARK-SZTAINER, D. Prevention of obesity and eating disorders: a consideration of shared risk factors. Health Education Research, 21(6), 770-782, 2006.

HALPERN, A. A epidemia de obesidade. Arquivos Brasileiros de Endocrinologia \& Metabologia, 43(3), 175-176. https://dx.doi.org/10.1590/S0004-273019990003, 1999.

HAN, B-C. Sociedade do cansaço. Petrópolis: Vozes, 2015.

LE BRETON, D. Adeus ao corpo: antropologia e sociedade. Campinas: Papirus, 2003.

MANCINI, M. C.; HALPERN, A. Tratamento farmacológico da obesidade. Arquivos Brasileiros de Endocrinologia \& Metabologia, v. 46, n. 5, p. 497-512, 2002.

MAROUN, K.; VIEIRA, V. Corpo: uma mercadoria na pós-modernidade. Psicologia em Revista, Belo Horizonte, v. 14, p.171-186, 2008.

NOVAES, J. V.; VILHENA, J. De cinderela a moura torta: sobre a relação mulher, beleza e feiura. Interações, v.8, n. 15, jan./jun. 2003. p. 9-36.

NOVAES, J. V. Mulher e beleza: em busca do corpo perfeito. Práticas corporais e regulação social. Tempo Psicanalítico, n. 33. Rio de Janeiro, SPID. p. 37-54, 2010a.

Com que Corpo eu vou? Sociabilidade e usos do corpo nas mulheres das camadas altas e populares. Rio de Janeiro: PUC Rio/ Pallas, 2010b.

Beleza e feiura: corpo feminino e regulação social. In: DEL PRIORI, Mary. História do Corpo no Brasil. São Paulo: UNESP, 2011.

ODGEN, J. Obesidade e qualidade de vida. Psicologia da Saúde, 2. ${ }^{a}$ Edição:161-224; 389, 2000. Disponível em: 〈www.actamedicaportuguesa.com/pdf/2006-19/3/247-250.pdf〉. Acesso em: 01 fev. 2018.

PIPHER, M. A. Adoração aos Deuses da Magreza. In: no mundo moderno. São Paulo: Ed. Martins Fontes, 1998.

O resgate de Ofélia - O drama da adolescência

RAND C.S, MACGREGOR A.M. Successful weight loss following obesity surgery and the perceived liability of morbid obesity. Int J Obes. Sep;15(9):577-9, 1991.

RIBEIRO, M.; ZORZETTO, R. O avesso de Narciso. Revista Pesquisa Fapesp, v. 103, 2004.

ROBERTSON, L. E MARCIA, L. Evolutionary Perspectives on Human Nutrition: The Influence of Brain and Body Size on Diet and Metabolism. American Journal of Human Biology, Rio de Janeiro, v. 6, p. 77- 88, 1994.

SANT'ANNA, D. B. Políticas do corpo: elementos para uma história das práticas corporais. São Paulo: Estação Liberdade, 1995.

Corpos de passagem. Ensaios sobre a subjetividade contemporânea. 2. ed. São Paulo: Estação Liberdade, 2005.

SEGAL, A.; FANDIÑO, J. Bariatric surgery indications and contraindications. Revista de Psiquiatria do Rio Grande do Sul, p. 68-72, 2002.

\section{POLÊM!CA $\mid$ LABORE}

Polêmica - Revista Eletrônica da Uerj - Rua São Francisco Xavier, 524, $1^{\circ}$ andar

bloco D, sl.1001 • Tels.: +55 21 2334-4088/4087 • http://www.e-publicacoes.uerj.br/index.php/polemica/index http://www.labore.uerj.br • laboreuerj@yahoo.com.br 
SONTAG, S.A. A doença como metáfora. Rio de Janeiro: Graal; 1984.

THE LANCET. Trends in adult body-mass index in 200 countries from 1975 to 2014: a pooled analysis of 1698 population-based measurement studies with $19 \cdot 2$ million participants. Disponível em: <http://www.thelancet.com/journals/lancet/article/PIIS0140-6736(16)30054-X/fulltext>. Acesso em: $01 \mathrm{fev.}$ 2018.

VIANNA, M. Da geladeira ao divã: Psicanálise da compulsão alimentar. Curitiba: ed. Appris, 2016.

WILliAM, R.; ROBERTSON, L. Rethinking the Energetics of Bipedality. Current Anthropology, Vol. 38, p. $304-309$, abr. 1997.

WORLD HEALTH ORGANIZATION. Obesity and overweight. Key Facts. 2014. Disponível em: <http://www.who.int/mediacentre/factsheets/fs311/en/>. Acesso em: 01 fev. 2018.

WORLD HEALTH ORGANIZATION. Preventing chronic diseases: a vital investment. Geneva: World Health Organization/Ottawa: Public Health Agencyof Canada; 2005.

Recebido em: 01/02/2018.

Aceito em: 02/03/2018.

\section{POLÊM!CA $\mid$ LABORE}

